First Peoples Child \& Family Review

A Journal on Innovation and Best Practices in Aboriginal Child Welfare Administration,

Research, Policy \& Practice

\title{
Ensuring Knowledge Transmission in the Aboriginal Child Welfare Field
}

\section{Marlyn Bennett}

Volume 3, Number 1, 2007

URI: https://id.erudit.org/iderudit/1069522ar

DOI: https://doi.org/10.7202/1069522ar

See table of contents

Publisher(s)

First Nations Child and Family Caring Society of Canada

ISSN

1708-489X (print)

2293-6610 (digital)

Explore this journal

Cite this document

Bennett, M. (2007). Ensuring Knowledge Transmission in the Aboriginal Child Welfare Field. First Peoples Child \& Family Review, 3(1), 5-9.

https://doi.org/10.7202/1069522ar 
First Peoples Child \& Family Review

A Journal on Innovation and Best Practices in Aboriginal Child Welfare

Administration, Research, Policy \& Practice

Volume 3, Number 1, 2007, pp. 5-9

\title{
Ensuring Knowledge Transmission in the Aboriginal Child Welfare Field
}

\author{
Marlyn Bennett, Co-ordinating Editor
}

This issue of the First Peoples Child \& Family Caring Society is the third volume produced by the Caring Society since our first inaugural issue was released in 2004. It demonstrates our commitment to ensuring knowledge transmission in the field of Aboriginal/First Nations child welfare. An important aspect of knowledge transmission is the need to ensure that the knowledge generated by the authors within the journal, as well as how the journal is prepared, is shared with the wider community. The collection of essays in this volume details distinctive issues that confront many Aboriginal/ First Nations and child welfare and social service agencies on a day to day basis, whether they are located on reserve, or in rural or urban localities. Issues around identify formation in relation to adoption and suicide prevail as the top themes within this volume. All of the 10 articles in this edition weave together important elements of storytelling and Indigenous knowledge that are unique among Aboriginal practitioners and community researchers.

Naturally, one would assume that children apprehended by child welfare agencies will be safely cared for by the agencies tasked with children's well-being and one would expect these same children participate and have access to all the services and programs that child welfare agencies are typically required to provide. For Aboriginal children residing on-reserve, in particular, their safety is at an increased risk, not because agencies are incapable of taking on this responsibility but because these agencies are inadequately resourced and funded to do so. The first article in this volume Keeping First Nations Children at Home: A Few Federal Policy Changes Could Make a Big Difference, succinctly summarizes the insufficient funding environment in which First Nations child welfare agencies must currently operate. Wien, Blackstock, Loxley and Trocmé indicates that although First Nations Child and Family Agencies are under funded by the Department of Indian and Northern Affairs, this can be alleviated through the adoption of four policy changes to the funding formula which may have better outcomes for children in care. They note firstly that key components of the funding formula to FN CFS agencies have not been augmented despite increases in cost of living factors - an increase in funding would help alleviate core agency funding around salary and benefits for executive directors, financial officers and agency board. Secondly, government incentive structures being what they currently are only permit FN CFS agencies to apprehend children not reimburse agencies 
for costs or provide resources related to work that would help children stay at home with their families of origin. Furthermore, they note that staff within First Nations CFS agencies must also contend with jurisdictional disputes that further exasperates operating problems from inadequate funding and services. Lastly, Wien, Blackstock, Loxley and Trocmé note that a lack of management information systems also further exasperate the work required by agencies in that such technological infrastructures would be useful for exchanging quantitative information within and between agencies and would assist in research that would contribute strategic planning for the future and for understandings the effectiveness of programs.

The next article The Politics of Kith and Kin: Observations on the British Columbia Government's Reaction to the Death of Sherry Charlie, written by Gerald Craddock provides a prime example of risk that First Nations CFS agencies undertake when under funded by the federal government. Craddock examines events around the death of a First Nations child who was placed and eventually killed in a Kith and Kin arrangement. Although Kith and Kin arrangements have been identified as a culturally conducive practice for Aboriginal children in care, it has not always a practice that First Nations agencies have control over. Craddock examines the hazards faced by First Nations child welfare agencies that get drawn into child welfare policies, which may, have little or no bearing on how they actually conduct child welfare in their communities and how they would wish to develop those services in the future. In examining the political climate of child welfare with regard to the Sherry Charlie case Craddock seeks to raise questions about the appropriate role of government representatives and experts in preserving established practices when confronted with influence wielded by elected officials and other interest groups seeking to further their own political, economic, and social agendas.

Through storytelling Nancy MacDonald provides a glimpse of her experiences in child welfare over the last 25 years in Reflections of a Mi'kmaq Social Worker on a Quarter of a Century Work in First Nations Child Welfare. As a Mi'kmaq social worker MacDonald draws upon her first interaction with a young Aboriginal child. The single act of placing the First Nations child into non-Aboriginal care triggered multiple losses for the child in MacDonald's story. The child became lost to herself, her family, community as well as lost to her culture and her heritage. Such is the case for all Aboriginal children who come into contact with the child welfare system as MacDonald notes that the story of the young girl in her article continues to be retold in exactly the same manner with the same outcomes for most Aboriginal children. MacDonald notes that schools of social work, through the principles of social just, can take a lead role on becoming decolonizing agents to First Nations peoples in Canada.

Jeannine Carriere's submission Promising Practice for Maintaining Identities in First Nations Adoption reflects on her PhD study regarding the importance of identity to First Nation individuals who have been adopted. The findings from her research indicate that there is a causal relationship between connection to birth family, community and ancestral knowledge, adoption and health. The overarching theme expressed by most adoptees is that loss of identify may contribute to impaired physical, spiritual, mental and emotional health for First Nation Adoptees. Carriere also provides 
suggestions on how identity can be preserved in First Nations adoptions through programs, policies and practice.

Adoption and an examination of early child welfare practice with First Nations peoples was also the focus of the following article, Identity Lost and Found: Lessons from the Sixties Scoop by Raven Sinclair. Sinclair's article points to recent research that indicates that some Aboriginal adults once adopted as children have found consolation and stronger identity formation by re-acculturating with their birth cultures and contextualizing their adoption experiences within colonial history. The adoption history in Canada is examined along with an examination of issues around transracial adoption through the lens of psychology theories to aid in understanding identity conflicts facing Aboriginal adoptees.

Michael Hart's piece on Indigenous Knowledge and Research: The míkiwáhp as a Symbol for Reclaiming our Knowledge and Ways of Knowing illustrates the inherent symbolisms of Indigenous knowledge and research as expressed through the use of a Cree lodge. The elements of the lodge help tie together symbolic and collective elements of Indigenous knowledge and how it is similar to some mainstream research paradigms which guide research. Another indigenous tool is also covered in this issue. The use of the Medicine Wheel as an effective tool for examining anti-oppressive practices in A Way of Life: Indigenous Perspectives on Anti-Oppressive Living by Robina Thomas and Jacquie Green.

Here be Dragons! Reconciling Indigenous and Western Knowledge to Improve Aboriginal Child Welfare speaks of the need for Aboriginal and non-Aboriginal child welfare structures to begin working together. It describes one such approach being undertaken in Alberta under the "Making Our Hearts Sing" initiative which reflects not only on the impact of residential schools and foster care on Aboriginal children but on mainstream's professional beliefs and assumptions about child welfare services. The Making Out Hearts Sing initiative is aimed at building collaboration among child welfare stakeholders and Aboriginal communities to examine the delivery of child welfare in Aboriginal communities and to begin creating innovative, effective and practical approaches to child welfare that are more in keeping with traditional Aboriginal worldviews that will contribute to reconciliation, healing and increased community capacity.

The last two submissions are students' submissions that speak to the issue of identity formation and the impact that identity has on the development of young Aboriginal people and the risks of suicide ideation and suicide. John Cournane's short article Are Rural American Indian adolescents becoming a Race of Angels? centers on the importance of identify formation and development in young Aboriginal persons in the early years of education. He notes that positive identity development at an early age helps ensure a reduction in adolescent suicides and improves ego development as children mature. In Re-examining issues behind the loss of family and culture and the impact on Aboriginal Youth Suicide Rates, Kristine Morris, explores through the prevailing literature, issues around culture loss and lack of cultural identity and the correction with suicide risk among young Aboriginal persons. Ways of reconnecting culture and ways of building identity for Aboriginal children in care are explored including some of the ways this has been hindered for children and youth who come into care. 


\section{Future Developments}

The creation of the First Peoples Child \& Family Review has certainly played a significant role in filling the gap in knowledge production around the voices and perspectives of those working in the Aboriginal child welfare field. The First Peoples Child \& Family Review has worked to ensure this knowledge is captured using the OCAP principles as established by the National Aboriginal Health Organization. The principles of ownership, control, access and possession (OCAP) as outlined in Schnarch (2004), basically relate to the collective ownership of group information; First Nations control over research and information; First Nations' management of access to their data and physical possession of that data.

Our Elders continually remind us that this generation has a responsibility to share the knowledge with the next generation and to ensure that this information is transferred to others (youth specifically) who will help in disseminating this information across various communities. Indeed, the importance of mentoring youth to help produce the journal was highlighted in the inaugural issue of this journal (Bennett, 2004, p. 4). Youth involvement is important to the viability and future of the journal. The addition of an Aboriginal youth editor to the staff overseeing the production of the First Peoples Child \& Family Review journal will be instrumental to Caring Society/ First Nations Research Site's goal of ensuring knowledge transmission through mentorship, sharing knowledge within communities, as well as assuring that young people gain valuable skills that will contribute to their research and publishing capacities. It is also in line with principles that the Caring Society has established regarding the engagement of young people. The Caring Society acknowledges that it is critical we support, nurture and respectfully engage young people in the work that our organization is mandated to provide. A commitment to engage youth means that we are committed to a relationship that goes beyond a project or a program (see Declaration of Accountability on the Ethical Engagement of Young People and Adults in Canadian Organizations).

Over the last two years the journal has been successful as a resource utilized by many students and instructors at the university level. Numerous copies of the journal are available through various libraries across Canada. In addition to being available for free from the Caring Society's website, the journal can also be accessed through Lund University's Directory of Open Access Journals (DOAJ, www.doaj.org) in Sweden and through EBSCO Publishing, an information source for millions of researchers in thousands of institutions worldwide (www. ebsco.com). This success has meant that hits to the Caring Society's online has increased considerably (on average, there are over 550 hits to the journal's webpage monthly). To date, there have been over 6,668 hits to the journal website since the beginning of the 2006 year. Increased interest in the journal in addition to increased responses to our Call for Papers means that we published on average 10 articles per issue. This indicates to us that our journal has become an important resource to many researchers, academic institutions and community members as a credible publishing entity. The early foresightedness and recognition of such a publication by our editorial board attests to the fact that open access to our journal is having a greater research impact than we expected (Antelman, 2004) not only among Aboriginal child welfare 
practitioners but also among non-Aboriginal practitioners, researchers, administrators, including various learning institutions as well as at both levels of government.

In the coming future we hope to hire a youth from within Winnipeg who will assist the co-ordinating editor in learning about the publishing process. We hope in the process this individual, in turn, will help mentor others from within the Aboriginal child welfare sector who might wish to write for publication in our journal. It has been our intention since the journal's inception to hire an Aboriginal youth who will be mentored in all aspects of producing the journal and we have begun to look at ways to help us make this aspiration a reality. We feel that this position will be a long term opportunity and youth involvement is mandatory to the objectives and goals of our organization and the journal. Youth will have an opportunity to learn all aspects of research and publishing which will help strengthen our ability to maintain our cultures, our knowledges and contribute to culturally congruent research in the Aboriginal child welfare field. By involving youth in the production of our journal, we will be keeping the diversity of Aboriginal culture and knowledge alive and contemporary. Mentoring youth in the process of producing the journal from the beginning to end of each issue will assist the First Nations Child \& Family Caring Society in furthering the transmission of knowledge which our Elders say is a significant responsibility that must be shared, a responsibility for which we take seriously.

\section{Bio}

Marlyn is the Director of Research for the Winnipeg based First Nations Research Site of the First Nations Child and Family Caring Society of Canada and the co-ordinating editor and founder of the First Peoples Child \& Family Review.

\section{References}

Antelman, K. (2004). Do Open-Access Articles Have a Greater Research Impact? College \& Research Libraries News, 65(5): 372282. Retrieved September 9th, 2006 from http://eprints.rclis.org/archive/00002309/01/ do open access_CRL.pdf.

Alderman, J., Balla, S., Khanna, N. and Blackstock, C. (2006). Declaration of Accountability on the Ethical Engagement of Young People and Adults in Canadian Organizations. Ottawa, ON: First Nations Child \& Family Caring Society of Canada.

Bennett, M. (2004). Editorial: Learning the Process of Publishing "Voices and Perspectives" on Indigenous knowledge in the Child Welfare Field. In First Peoples Child \& Family Review: A Journal on Innovation and Best Practices in Aboriginal Child Welfare Administration, Research, Policy and Practice, 1(1), p.2-4. Available online at: http://www.fncfcs.com/pubs/ vol1num1/vol1num1Editorial.pdf.

Schnarch, B. (2004) 'Ownership, Control, Access and Possession (OCAP) or SelfDetermination Applied to Research." Journal of Aboriginal Health, 1(1): 80-95. 